\title{
Desempenho, digestibilidade da matéria seca e comportamento ingestivo de novilhos holandeses alimentados com diferentes dietas em confinamento
}

\author{
Performance, dry matter digestibility and feeding behavior of \\ Holstein steers fed different diets in confinement
}

\author{
Mikael Neumann ${ }^{1 *}$; Danúbia Nogueira Figueira ${ }^{2}$; Robson Kyoshi Ueno ${ }^{3}$; \\ Guilherme Fernando Mattos Leão ${ }^{4}$; Julio Cezar Heker Junior ${ }^{5}$
}

\section{Resumo}

O objetivo do trabalho foi avaliar o desempenho, a digestibilidade aparente de matéria seca e o comportamento ingestivo de novilhos holandeses alimentados com diferentes dietas em sistema de confinamento. Foram utilizados 36 bezerros da raça Holandesa, provenientes de mesmo rebanho, com idade média de 192 dias e peso vivo médio inicial de $221 \mathrm{~kg}$. As dietas experimentais foram constituídas de: $\mathrm{T}_{1}$ : Dieta 100\% concentrado; $\mathrm{T}_{2}$ : Dieta 55\% concentrado + silagem de milho; e $\mathrm{T}_{3}$ : Dieta $55 \%$ concentrado + feno de aveia, e seis repetições, onde cada repetição foi uma baia com dois animais. Houve diferença significativa entre os tratamentos, sendo que o tratamento composto pela dieta $100 \%$ concentrado teve resultados de desempenho superior, com ganho médio diário de 1,350 $\mathrm{kg} \mathrm{dia}^{-1}$; conversão alimentar de 5,28 e Consumo de matéria seca de 6,84. Avaliou-se também que a dieta 100\% ainda influenciou o comportamento ingestivo, sendo que os tempos para ruminação, consumo alimentar e ingestão de água são respectivamente 2,$75 ; 1,14 ; 0,15$ horas dia $^{-1}$. A digestibilidade da matéria seca também teve diferença significativa para a dieta $100 \%$, sendo que esta foi da ordem de $76,37 \%$. A dieta $100 \%$ concentrado se mostrou, em termos de desempenho, uma alternativa interessante para a terminação de novilhos holandeses.

Palavras-chave: Consumo de matéria seca, conversão alimentar, dietas de alto grão, ganho de peso médio diário

\begin{abstract}
The aim of the study was to evaluate the performance, apparent digestibility of dry matter and feeding behavior of Dutch steers fed different diets in feedlot. Were used 36 Holstein calves, from the same herd, with an average of 192 days and an average body weight of $221 \mathrm{~kg}$ age. The experimental diets consisted of: T1: $100 \%$ concentrate diet; T2: $55 \%$ concentrate diet + corn silage; and T3: $55 \%$ concentrate diet + oat hay, and six replicates, where each replicate was a stall with two animals. Was no significant difference between treatments, and the treatment consists of the $100 \%$ concentrate diet had higher performance
\end{abstract}

${ }^{1}$ Eng $^{\mathrm{o}} \mathrm{Agr}^{\mathrm{o}}$, Prof. Dr., Curso de Pós-Graduação em Produção Vegetal da Universidade Estadual do Centro-Oeste, UNICENTRO, Guarapuava, PR. E-mail: mikaelneumann@hotmail.com

2 Médico Veterinário, Discente de Doutorado, Curso de Pós-Graduação em Zootecnia, Universidade Federal do Rio Grande do Sul, UFRGS, Porto Alegre, RS. E-mail: robsonueno@hotmail.com

3 Médica Veterinária, Discente de Mestrado em Agronomia, Curso de Pós-Graduação em Produção Vegetal, UNICENTRO, Guarapuava, PR. E-mail: danmedvet07@gmail.com

${ }^{4}$ Médico Veterinário, Discente de Mestrado em Zootecnia, Universidade Estadual de Maringá, UEM, Maringá,PR. E-mail: gfleao@hotmail.com

5 Discente de Graduação de Medicina Veterinária, UNICENTRO, Guarapuava, PR. E-mail: jr_heker@hotmail.com

* Autor para correspondência 
results with an average daily gain of $1.350 \mathrm{~kg} \mathrm{day}^{-1}$; and feed conversion of 5.28 dry matter intake of 6.84. We evaluated also the $100 \%$ diet also influenced the feeding behavior, and the time for rumination, food consumption and water intake are respectively $2.75 ; 1.14 ; 0.15$ hours day ${ }^{-1}$. The digestibility of dry matter was also a significant difference to the diet $100 \%$, and this was around $76.37 \%$. The diet showed $100 \%$ concentrate in terms of performance, an interesting alternative for termination of Holstein steers.

Key words: Average daily weight gain, all grain diets, dry matter intake, feed conversion

\section{Introdução}

A atividade leiteira vem cada vez mais se profissionalizando no país, e com o aumento da intensificação, também é crescente o número de preocupações do produtor rural. Uma dessas preocupações é o destino dos machos leiteiros. Sabe-se que os bezerros machos, especialmente os pertencentes a raças leiteiras de grande porte, como Holandês e Pardo Suíço, são sacrificados após o nascimento por representarem um custo dito como "não produtivo" nos sistemas de produção leiteira, embora possuam ganho de peso interessante (ROCHA et al., 1999).

De acordo com Freitas Neto (2009), o Brasil deixa de produzir milhares de toneladas de carne pelo não aproveitamento do bezerro leiteiro como animal destinado ao abate e pelo mau manejo quando se cria esta categoria, enquanto que países como Estados Unidos, Austrália e Nova Zelândia utilizam de forma efetiva estes animais para a produção de carne. Porém, como não são animais especializados para corte e devem ser desmamados precocemente, necessitam de cuidados e tecnologias diferenciadas desde o nascimento, principalmente no que diz respeito ao manejo alimentar e ao sistema de produção adotado com vistas a obter melhor eficiência biológica e econômica na criação. Rocha et al. (1999) ainda ressalta que bovinos com grau de sangue da raça Holandesa, possuem um menor desempenho quanto submetidos à sistemas de produção extensivos.

O confinamento é um modelo de sistema de produção intensivo bastante difundido, conforme Cardoso (1996), os animais a serem confinados, além de apresentar sanidade adequada, devem possuir estrutura corporal adequada e potencial para ganho de peso. Estas características são contempladas por machos da raça Holandesa, onde o confinamento surge então como uma estratégia interessante para obtenção de sucesso na produção de carne com bovinos de genética leiteira e, embora eleve o custo de produção, pode aumentar o giro de receitas da propriedade. O correto manejo adotado no confinamento, como formação de lotes homogêneos, dieta balanceada, higiene e monitoramento constante dos animais, são fatores que predispõe melhorias no estado sanitário e desempenho produtivo, tornando viável a produção de animais com alta exigência, como bezerros Holandeses.

Em comparação com outros países, o Brasil ainda contabiliza baixo percentual de animais confinados, no entanto, a prática do confinamento se torna cada vez mais presente com relação aos anos anteriores, fato este justificado pelo aumento de grãos no mercado, concomitante com o aumento das alternativas alimentares para compor rações (LEÃO et al., 2012; SIMAS et al., 2008). De mesma forma, procura-se a viabilidade econômica dos sistemas produtivos, o que pode ser alcançado pelo aumento do desempenho produtivo dos animais confinados, fato esse que pode ser mensurado, através das variáveis de consumo, como por exemplo, o ganho de peso, a conversão alimentar e o consumo alimentar (LOPES et al., 2008).

Silva (2009) salienta que, através desta intensificação em busca da viabilidade econômica dentro dos sistemas produtivos, cada vez mais procura-se a maior inclusão de alimentos concentrados, visando maximizar não somente o desempenho dos animais, mas também na deposição de gordura, na diminuição dos custos operacionais 
de confecção e fornecimento de alimento aos animais. Desta forma, a dieta 100\% concentrado, dieta esta que exclui totalmente o volumoso, surge como opção interessante em épocas de preços acessíveis aos grãos ou em casos de excedentes de produção agrícola (UENO, 2012).

Dietas com maiores teores de concentrado, especialmente em dietas com milho inteiro, teoricamente, possuem melhores conversões alimentares, independente de processamento (GRANDINI, 2009). Em contraponto a isto, valendo-se do fato do aproveitamento de energia advinda da forragem pelo animal ruminante, Ueno (2012) ressalta a importância da silagem de milho como alimento conservado, visto que gera bom desempenho para bovinos de corte em sistemas de terminação em confinamento, apresentando ganhos de peso interessantes. Ademais, considera-se a silagem de milho como alimento de importância para a terminação de bovinos em confinamento com vistas ao seu alto teor energético, baixo teor de fibra, alta produção de matéria seca por área, além do bom padrão de fermentação e bem como a ausência de obrigatoriedade do uso de aditivos (PEREIRA et al., 2004).

O objetivo deste trabalho foi de avaliar o desempenho, a digestibilidade aparente de matéria seca e o comportamento ingestivo de novilhos holandeses alimentados com diferentes dietas em sistema de confinamento.

\section{Material e Métodos}

O experimento foi conduzido nas instalações do Núcleo de Produção Animal (NUPRAN) do Setor de Ciências Agrárias e Ambientais da Universidade Estadual do Centro-Oeste (UNICENTRO), em Guarapuava-PR, e em parceria com o Instituto Paranaense de Assistência Técnica e Extensão Rural (EMATER-PR) e Cooperativa Agrária Agroindustrial.

O delineamento experimental foi o inteiramente casualizado, constituído de três tratamentos com seis repetições, onde cada repetição foi uma baia com dois animais. Os tratamentos foram: $\mathrm{T}_{1}$ : Dieta 100\% concentrado ( $80 \%$ grão de milho inteiro $+20 \%$ de núcleo protéico); $\mathrm{T}_{2}$ : Dieta $55 \%$ concentrado $+45 \%$ silagem de milho; e $\mathrm{T}_{3}$ : Dieta $55 \%$ concentrado + $45 \%$ feno de aveia.

Foram utilizados 36 novilhos da raça Holandesa com idade média inicial de 192 dias de vida e peso vivo de $221 \mathrm{~kg}$. Os animais foram alojados em confinamento, divididos em 18 baias semi-cobertas com área de $15 \mathrm{~m}^{2}$ cada $(2,5 \mathrm{~m}$ x 6,0 m), com um comedouro de concreto e um bebedouro metálico regulado por bóia automática. O experimento teve duração de 210 dias, sendo os 35 dias iniciais para adaptação dos animais às dietas e instalações experimentais e, sequencialmente, cinco períodos de avaliação com 35 dias cada.

Os animais foram alimentados duas vezes ao dia, às 6:00 e às 17:30 horas, onde o consumo voluntário dos alimentos foi registrado diariamente através da pesagem da quantidade oferecida e das sobras do dia anterior. As rações experimentais foram formuladas visando obter relação isonitrogenada entre os tratamentos, eas quantidades de alimentos fornecidos foram reguladas diariamente para a obtenção das devidas proporções. O ajuste no fornecimento da quantidade de ração, de todos os tratamentos, foi realizado diariamente, considerando sobra de $5 \%$ da matéria seca oferecida. A alimentação foi realizada na forma de ração totalmente misturada (RTM).

As misturas concentradas foram elaboradas na fábrica de rações comerciais da Cooperativa Agrária Agroindustrial, localizada em Guarapuava-PR. Na preparação do núcleo proteico fornecido em $\mathrm{T}_{1}$ e do concentrado fornecido em $\mathrm{T}_{2}$ e $\mathrm{T}_{3}$, foram utilizados os seguintes alimentos: farelo de soja, casca de soja, farelo de trigo, radícula de malte, cevada, grãos de milho moídos, gérmen de milho, calcário calcítico, fosfato bicálcico, uréia pecuária, premix vitamínico e mineral, sal comum e monensina sódica.

A adaptação dos animais à dieta 100\% concentrado ocorreu gradativamente, de forma que 
nos primeiros quatro dias foram fornecidos $1,2 \%$ do peso vivo da mistura de concentrado (núcleo proteico: $20 \%$ + milho grão inteiro: $80 \%$ ) e silagem de milho à vontade. Em um segundo momento, do quarto ao oitavo dia passou-se a fornecer $1,6 \%$ da mistura de concentrado e silagem de milho ad libitum, sendo que a partir do nono dia interrompeuse totalmente o fornecimento da fonte de alimento volumoso, disponibilizando somente a mistura concentrada no cocho de forma ad libitum. $\mathrm{Na}$ adaptação dos animais do $\mathrm{T}_{2}$ e $\mathrm{T}_{3}$, realizou-se de imediato o fornecimento das dietas experimentais, visto que já recebiam suplementação concentrada na proporção de $1,4 \%$ do peso vivo.

Os animais foram pesados após jejum de sólidos de 12 horas, no início e fim do período experimental, com pesagens intermediárias a cada 35 dias. As variáveis avaliadas, nos cinco períodos de avaliação foram os consumos médios diários de matéria seca expressos em kg.animal ${ }^{-1}$ dia $^{-1}$ e por $100 \mathrm{~kg}$ de peso vivo, o ganho de peso médio diário e a conversão alimentar.
Foram realizadas amostras compostas da silagem de milho, do feno de aveia e dos concentrados de cada tratamento durante os períodos de avaliação do confinamento. As amostras dos alimentos foram levadas à estufa com ventilação a $55^{\circ} \mathrm{C}$ por 72 horas para determinação da matéria parcialmente seca. As amostras pré-secas foram moídas em moinho tipo Willey com peneira de $1 \mathrm{~mm}$ de diâmetro e conduzidas posteriormente para análise químicobromatológica. Nas amostras pré-secas, foram estimados os teores de matéria seca, matéria mineral e proteína bruta, segundo técnicas descritas na AOAC (1995). Os teores de fibra em detergente neutro foram obtidos conforme método de Van Soest, Robertson e Lewis (1991) com a-amilase termo-estável e de fibra em detergente ácido segundo Goering e Van Soest (1970). Os resultados das análises químico-bromatológicas encontram-se na Tabela 1 .

Tabela 1. Teores médios de matéria seca (MS), proteína bruta (PB), fibra em detergente neutro (FDN), fibra em detergente ácido (FDA), matéria mineral (MM), cálcio (Ca) e fósforo (P) dos alimentos e dietas experimentais fornecidas para novilhos Holandeses confinados.

\begin{tabular}{cccccccc}
\hline \multirow{2}{*}{ Alimentos/Tratamentos } & \multicolumn{7}{c}{ Análises químico-bromatológicas, \% da MS } \\
\cline { 2 - 7 } & $\mathrm{MS}$ & PB & FDN & FDA & MM & Ca & $\mathrm{P}$ \\
\cline { 2 - 7 } Núcleo proteico $\left(\mathrm{T}_{1}\right)$ & 95,03 & 38,50 & 32,47 & 11,36 & 13,81 & 4,04 & 1,13 \\
Grão de milho $\left(\mathrm{T}_{1}\right)$ & 93,51 & 7,42 & 14,08 & 5,10 & 1,14 & 0,25 & 0,03 \\
Concentrado $\left(\mathrm{T}_{2} \mathrm{e} \mathrm{T}_{3}\right)$ & 92,94 & 19,84 & 30,13 & 14,62 & 4,48 & 1,22 & 0,54 \\
Silagem de milho $\left(\mathrm{T}_{2}\right)$ & 32,82 & 6,23 & 52,50 & 31,15 & 2,40 & 0,20 & 0,23 \\
Feno de aveia $\left(\mathrm{T}_{3}\right)$ & 93,15 & 6,17 & 68,08 & 44,86 & 4,21 & 0,43 & 0,21 \\
\hline 100\% concentrado $\left(\mathrm{T}_{1}\right)$ & 93,81 & 13,64 & 17,76 & 6,35 & 3,67 & 1,01 & 0,25 \\
Concentrado+Silagem $\left(\mathrm{T}_{2}\right)$ & 65,89 & 13,72 & 40,20 & 22,06 & 3,54 & 0,76 & 0,40 \\
Concentrado+Feno $\left(\mathrm{T}_{3}\right)$ & 93,03 & 13,69 & 47,21 & 28,23 & 4,36 & 0,86 & 0,39 \\
\hline
\end{tabular}

Fonte: Elaboração dos autores.

A avaliação do comportamento ingestivo foi realizada em um período de 72 horas contínuas. As mensurações foram realizadas por um observador em cada baia, e as leituras das atividades comportamentais foram tomadas a cada 3 minutos. As variáveis analisadas constaram da mensuração do tempo despendido em ócio, ruminação, abeberação (ingestão de água) e alimentação, expressas em horas por dia. Concomitantemente, procedeu-se a avaliação da digestibilidade aparente da matéria seca das dietas experimentais. Coletouse a produção total de fezes de cada unidade 
experimental, no momento da eliminação da excreta, as quais foram pesadas e amostradas em cada turno de 6 horas. Completando-se as 72 horas, as fezes foram homogeneizadas para a formação de uma amostra composta representativa dos 3 dias de avaliação. As amostras foram desidratadas em estufa de ar forçado a $55^{\circ} \mathrm{C}$ até obter peso constante. Pelas amostras das fezes secas, foi determinado o coeficiente de digestibilidade aparente (CD) pela expressão:

$\mathrm{CD}(\%)=(\mathrm{g}$ de $\mathrm{MS}$ consumida $-\mathrm{g}$ de $\mathrm{MS}$ excretada) / g de MS consumida X 100.

Os dados coletados para as variáveis relativas ao desempenho animal, comportamento ingestivo e digestibilidade aparente da matéria seca foram submetidos à análise de variância com comparação das médias pelo teste Tukey a 5\% de significância, por intermédio do programa estatístico SAS (1993).

Os dados relativos ao desempenho animal também foram submetidos à análise de regressão polinomial, considerando a variável período (175 dias), por intermédio do procedimento PROC REG do programa estatístico SAS (1993).

\section{Resultados e Discussão}

$\mathrm{Na}$ Tabela 1 encontram-se os teores médios de matéria seca, proteína bruta, fibra em detergente neutro, fibra em detergente ácido, matéria mineral, $\mathrm{Ca}$ e $\mathrm{P}$ dos alimentos e dietas experimentais.

Não houve interação significativa $(\mathrm{P}>0,05)$ entre tratamentos e períodos de avaliação para o ganho de peso médio diário, conversão alimentar, e consumo de matéria seca por animal e por peso vivo.

Conforme a Tabela 2, houve diferença estatística entre os tratamentos $(\mathrm{P}<0,05)$ para ganho de peso diário e conversão alimentar. Animais alimentados com a dieta $100 \%$ concentrado apresentaram ganhos de peso superiores comparativamente a dieta com feno $\left(1,350\right.$ vs $1,226 \mathrm{~kg}$ animal $\left.{ }^{-1} \mathrm{dia}^{-1}\right)$. A dieta com silagem de milho proporcionou ganhos intermediários, não diferindo estatisticamente das demais $\left(1,278 \mathrm{~kg}_{\text {animal }}{ }^{-1} \mathrm{dia}^{-1}\right)$.

Tabela 2. Ganho de peso médio diário (GMD) e conversão alimentar (CA) de novilhos Holandeses alimentados com diferentes dietas em confinamento, conforme o período de avaliação.

\begin{tabular}{|c|c|c|c|c|c|c|}
\hline \multirow[b]{2}{*}{ Tratamentos } & \multicolumn{5}{|c|}{ Período de Confinamento } & \multirow[b]{2}{*}{ Média } \\
\hline & $\begin{array}{c}1^{\circ} \text { Período } \\
1-35 \text { dias }\end{array}$ & $\begin{array}{l}2^{\circ} \text { Período } \\
36-70 \text { dias }\end{array}$ & $\begin{array}{l}3^{\circ} \text { Período } \\
71-105 \text { dias }\end{array}$ & $\begin{array}{l}4^{\circ} \text { Período } \\
105-140 \text { dias }\end{array}$ & $\begin{array}{l}5^{\circ} \text { Período } \\
141-175 \text { dias }\end{array}$ & \\
\hline \multicolumn{7}{|c|}{ Ganho de peso médio diário, $\mathrm{kg}_{\text {animal }}{ }^{-1}$ dia $^{-1}$} \\
\hline $100 \%$ Concentrado & 1,537 & 1,469 & 1,368 & 1,085 & 1,291 & $1,350 \mathrm{a}$ \\
\hline Concentrado + Silagem & 1,267 & 1,178 & 1,232 & 1,334 & 1,378 & $1,278 \mathrm{ab}$ \\
\hline Concentrado+Feno & 1,046 & 1,371 & 1,232 & 1,101 & 1,389 & $1,226 \mathrm{~b}$ \\
\hline Média & 1,283 & 1,339 & 1,277 & 1,173 & 1,350 & \\
\hline Equação regressão* $^{*}$ & \multicolumn{6}{|c|}{ GMD: $1285 \mathrm{~kg} \cdot \mathrm{dia}^{-1}\left(\mathrm{R}^{2}: 0,0012 ; \mathrm{CV}: 12,6 \%\right.$; $\left.\mathrm{P}<0,7899\right)$} \\
\hline \multicolumn{7}{|c|}{ Conversão alimentar, kg de matéria seca/kg de ganho } \\
\hline $100 \%$ Concentrado & 3,75 & 4,17 & 5,38 & 6,90 & 6,20 & $5,28 \mathrm{c}$ \\
\hline Silagem de Milho & 4,58 & 5,75 & 6,53 & 6,55 & 6,72 & $6,03 \mathrm{~b}$ \\
\hline Feno de Aveia & 6,15 & 5,43 & 7,08 & 8,45 & 7,05 & $6,83 \mathrm{a}$ \\
\hline Média & 4,83 & 5,12 & 6,34 & 7,30 & 6,66 & \\
\hline Equação regressão* & \multicolumn{6}{|c|}{ CA: 4,2299+0,0173D (R²: 0,3217; CV: 20,8\%; $\mathrm{P}<0,0001)$} \\
\hline
\end{tabular}

Médias, seguidas por letras minúsculas, na coluna, diferem entre si pelo teste Tukey a 5\% de significância.

${ }^{*}$ D: Período de confinamento variando de 1 a 175 dias.

Fonte: Elaboração dos autores. 
Melhores conversões alimentares foram observadas em animais alimentados com dieta $100 \%$ concentrado, seguidos da dieta com silagem de milho e feno de aveia, apresentando valores de 5,28 vs 6,03 vs 6,83 kg de matéria seca consumida para cara $\mathrm{kg}$ de peso ganho, para os respectivos tratamentos.

Ueno (2012) analisando o uso de dieta 100\% concentrado com grão de milho inteiro em contraste com uma dieta composta por silagem de milho e concentrado em novilhos inteiros confinados da raça Canchim, observou ganhos médios diários semelhantes entre os dois tratamentos (1,564 vs $\left.1,461 \mathrm{~kg} \mathrm{dia}^{-1}\right)$, no entanto com diferença significativa de conversão alimentar (4,57 vs 6,67 $\mathrm{kg} \mathrm{kg}^{-1}$ ).

Por outro lado, Silva (2009) obteve resultados de desempenho ainda superiores analisando uma dieta composta por $75 \%$ de milho grão inteiro, $10 \%$ de casca de soja e $15 \%$ de núcleo proteico na alimentação de bovinos da raça Nelore com 28 meses de idade. Os resultados encontrados para ganhos médios diários e conversão alimentares são, respectivamente, $1,82 \mathrm{~kg}$ e 4,09 $\mathrm{kg}$. No entanto, pela idade mais tardia dos animais, um possível ganho compensatório pode estar associado para justificar o alto desempenho obtido.

Neumann et al. (2007) avaliando a alimentação de 36 novilhos Charolês com silagens de milho e sorgo associados a três níveis de concentrado obteve médias de desempenho com a silagem de milho semelhantes ao do presente estudo, sendo que o ganho médio diário e a conversão alimentar melhoraram com o aumento da inclusão de concentrado na dieta. Costa et al. (2002) usando silagem de milho e feno de aveia na alimentação de bovinos superprecoces observaram que independente do volumoso utilizado, não se obteve diferença significativa $(\mathrm{P}>0,05)$.

Em contrapartida, analisando um estudo com bezerros Holandeses alimentados com diferentes inclusões de volumoso na dieta, pode-se observar um decréscimo no ganho médio diário dos bezerros que possuíam uma alimentação composta por maior participação de volumoso, ao passo que a conversão alimentar piorou (SIGNORETTI et al., 1999a).

De acordo com a Tabela 3, houve diferença significativa $(\mathrm{P}<0,05)$ no consumo de matéria seca por animal e consumo em relação peso vivo entre os tratamentos. O consumo diário de matéria seca por animal foi distinto entre todos os tratamentos, sendo que a dieta composta por feno de aveia apresentou maiores valores $(8,17)$, seguida pelo tratamento com silagem de milho $(7,61)$ e por fim, o tratamento $100 \%$ concentrado $(6,84)$. De mesmo modo, o consumo em relação ao peso vivo também se mostrou distinto conforme os tratamentos, apresentando valores de 2,61 vs 2,36 vs 2,02\% do peso vivo, para os respectivos tratamentos.

Signoretti et al. (1999b), não observaram diferença significativa no consumo de matéria seca com relação ao aumento da inclusão de volumosos na dieta. Bürger et al. (2000) e Ribeiro (1997), ambos trabalhando também com novilhos Holandeses submetidos a alimentação com diferentes níveis de concentrado, não encontraram diferença significativa no consumo de matéria seca. Já Atwell et al. (1991) e Araújo (1997), por sua vez, encontraram resultados significativos com relação ao consumo de matéria seca.

Os consumos de proteína bruta, matéria seca digestível, fibra em detergente neutro e fibra em detergente ácido estão apresentados na Figura 1. Animais alimentados com dieta 100\% concentrado apresentaram, na média, consumo dos respectivos compostos nutricionais de 0,$933 ; 5,224 ; 1,215$ e $0,434 \mathrm{~kg}$ por animal. A dieta com silagem de milho proporcionou consumos médios de 1,044; 4,923; 3,059 e 1,679 kg por animal dos respectivos compostos nutricionais. Já a alimentação com feno de aveia, proporcionou consumos médios de 1,118; 5,$101 ; 3,857$ e 2,306 kg por animal, respectivamente. 
Tabela 3. Consumo de matéria seca diário por animal (CMSD) e em relação ao peso vivo (CMSP) de novilhos Holandeses alimentados com diferentes dietas em confinamento, conforme o período de avaliação.

\begin{tabular}{|c|c|c|c|c|c|c|}
\hline \multirow[b]{2}{*}{ Tratamentos } & \multicolumn{5}{|c|}{ Período de Confinamento } & \multirow[b]{2}{*}{ Média } \\
\hline & $\begin{array}{l}1^{\circ} \text { Período } \\
1-35 \text { dias }\end{array}$ & $\begin{array}{l}2^{\circ} \text { Período } \\
36-70 \text { dias }\end{array}$ & $\begin{array}{l}3^{\circ} \text { Período } \\
71-105 \text { dias }\end{array}$ & $\begin{array}{c}4^{\circ} \text { Período } \\
105-140 \text { dias }\end{array}$ & $\begin{array}{l}5^{\circ} \text { Período } \\
141-175 \text { dias }\end{array}$ & \\
\hline \multicolumn{7}{|c|}{ Consumo de matéria seca, $\mathrm{kg}_{\text {animal }}{ }^{-1}$ dia $^{-1}$} \\
\hline $100 \%$ Concentrado & 5,74 & 6,08 & 7,16 & 7,45 & 7,75 & $6,84 \mathrm{c}$ \\
\hline Concentrado+Silagem & 5,77 & 6,50 & 7,98 & 8,59 & 9,22 & $7,61 \mathrm{~b}$ \\
\hline Concentrado+Feno & 6,11 & 7,35 & 8,64 & 9,11 & 9,63 & $8,17 \mathrm{a}$ \\
\hline Média & 5,87 & 6,65 & 7,93 & 8,39 & 8,87 & \\
\hline Equação regressão* & \multicolumn{6}{|c|}{ CMSD: $5,2420+0,0218 \mathrm{D}(\mathrm{R} 2: 0,6187 ; \mathrm{CV}: 11,4 \% ; \mathrm{P}<0,0001)$} \\
\hline \multicolumn{7}{|c|}{ Consumo por $100 \mathrm{~kg}$ de peso vivo, $\%$} \\
\hline $100 \%$ Concentrado & 2,30 & 2,00 & 2,08 & 1,89 & 1,80 & $2,02 \mathrm{c}$ \\
\hline Concentrado + Silagem & 2,43 & 2,31 & 2,47 & 2,34 & 2,26 & $2,36 \mathrm{~b}$ \\
\hline Concentrado+Feno & 2,65 & 2,70 & 2,72 & 2,53 & 2,43 & $2,61 \mathrm{a}$ \\
\hline Média & 2,46 & 2,34 & 2,42 & 2,26 & 2,17 & \\
\hline Equação regressão* & \multicolumn{6}{|c|}{ CMSP: $2,5255-0,0019 \mathrm{D}$ (R2: 0,1001; CV: $12,3 \%$; $\mathrm{P}<0,0138)$} \\
\hline
\end{tabular}

Médias, seguidas por letras minúsculas, na coluna, diferem entre si pelo teste Tukey a 5\% de significância.

${ }^{*}$ D: Período de confinamento variando de 1 a 175 dias.

Fonte: Elaboração dos autores.

Com relação ao comportamento ingestivo, houve diferença estatística $(\mathrm{P}<0,05)$ entre os parâmetros de tempo de ruminação, ócio, consumo de alimento e ingestão de água. Também houve diferença significativa $(\mathrm{P}<0,05)$ entre tratamentos para a digestibilidade aparente da matéria seca das dietas experimentais (Tabela 4).

Os resultados obtidos por Ueno (2012) corroboram com os resultados encontrados no presente trabalho, sendo que a dieta composta por $100 \%$ concentrado, em ambos os estudos, apresenta menores valores no tempo de ruminação e consumo de alimento quando comparado com dietas com forragem. Missio et al. (2010), avaliando o comportamento ingestivo de 16 bovinos inteiros alimentados com diferentes níveis de concentrado na dieta, obtiveram resultados semelhantes ao do presente estudo. Neumann et al. (2009) observaram o comportamento ingestivo de animais alimentados com silagem de milho de diferentes tamanhos de partícula e alturas de colheita, onde silagens cortadas em altura maior e tamanho de partícula menor apresentaram menor tempo de ruminação.

Silva et al. (2005) avaliando a digestibilidade da matéria seca de 24 animais cruzados Holandês $\mathrm{X}$ Zebu, alimentados com dietas contendo concentrado e silagem de Brachiaria brizantha cv. Marandu em diferentes proporções (20:80; 35:65; 50:50; 65:35), observaram um comportamento linear da digestibilidade aparente, elevando-se com o aumento do nível de concentrado da dieta. Rode, Weakley e Satter (1985) avaliando vacas holandesas em lactação com cânulas ruminal e duodenal, alimentadas com diferentes níveis de volumoso na dieta, observaram aumento na digestibilidade a medida que a fração volumosa foi reduzida. $\mathrm{O}$ autor atribuiu ao aumento no teor de carboidratos não estruturais, estes mais digestíveis, em contraste a diminuição dos carboidratos estruturais, como provável causa do aumento da digestibilidade aparente da dieta. 
Figura 1. Consumo de compostos nutricionais por novilhos Holandeses alimentados com diferentes dietas em confinamento.
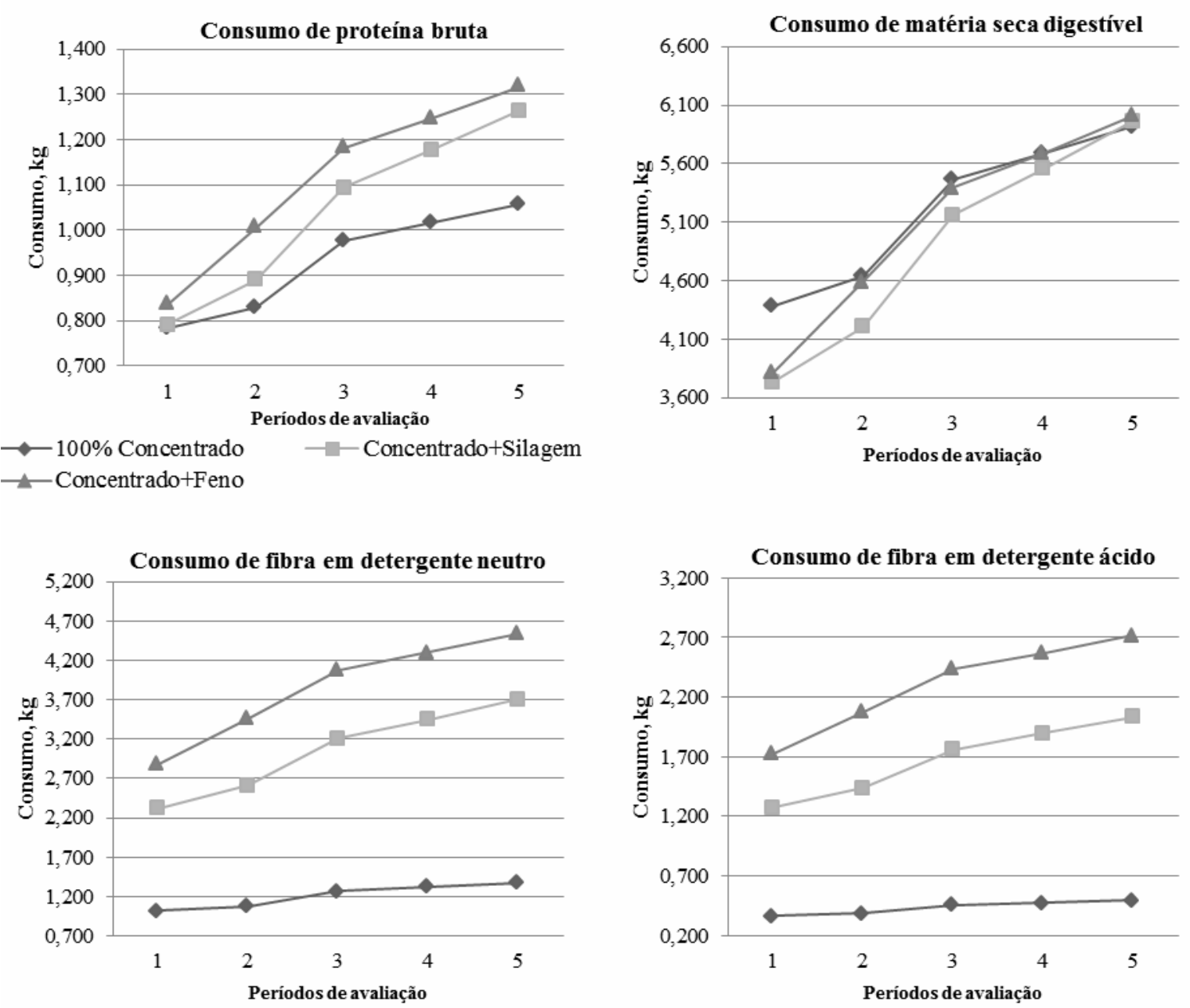

Fonte: Elaboração dos autores.

Tabela 4. Comportamento ingestivo e digestibilidade aparente da matéria seca apresentada por novilhos Holandeses alimentados com diferentes dietas em confinamento.

\begin{tabular}{|c|c|c|c|c|}
\hline \multirow[b]{2}{*}{ Atividades comportamentais } & \multicolumn{3}{|c|}{ Tratamentos } & \multirow[b]{2}{*}{ Média } \\
\hline & $\begin{array}{c}100 \% \\
\text { Concentrado }\end{array}$ & $\begin{array}{c}\text { Concentrado + } \\
\text { Silagem }\end{array}$ & $\begin{array}{c}\text { Concentrado }+ \\
\text { Feno }\end{array}$ & \\
\hline \multicolumn{5}{|c|}{ horas dia $^{-1}$} \\
\hline Tempo de ruminação & $2,75 \mathrm{~b}$ & $8,58 \mathrm{a}$ & $9,06 \mathrm{a}$ & 6,80 \\
\hline Tempo em ócio & 19,47 a & $12,22 \mathrm{~b}$ & $10,19 \mathrm{~b}$ & 13,96 \\
\hline Tempo de alimentação & $1,64 \mathrm{c}$ & $3,05 \mathrm{~b}$ & $4,52 \mathrm{a}$ & 3,07 \\
\hline Tempo de abeberação & $0,15 \mathrm{~b}$ & $0,16 b$ & $0,21 \mathrm{a}$ & 0,17 \\
\hline \multicolumn{5}{|c|}{$\%$ da matéria seca } \\
\hline Digestibilidade aparente & $76,37 \mathrm{a}$ & $64,69 \mathrm{~b}$ & $62,44 \mathrm{c}$ & 67,84 \\
\hline
\end{tabular}

Médias, seguidas por letras minúsculas, na linha, diferem entre si pelo teste Tukey a 5\% de significância.

Fonte: Elaboração dos autores. 


\section{Conclusão}

A utilização de dieta $100 \%$ concentrado apresenta vantagens bastante evidentes em termos de desempenho, consumo de matéria seca, digestibilidade aparente da matéria seca quando comparada aos demais tratamentos, sendo considerada, portanto, uma alternativa interessante para a terminação de novilhos de origem leiteira em confinamento. Os resultados de desempenho apresentados pelos novilhos Holandeses, em cada tratamento, servem como indicadores para a tomada de decisão na escolha do sistema alimentar mais indicado, lembrando que a viabilidade econômica é intimamente atrelada ao custo dos alimentos, que variam conforme região e época.

\section{Referências}

ARAÚJO, G. G. L. Consumo, digestibilidade, desempenho, composição corporal e exigências nutricionais de bezerros alimentados com dietas contendo diferentes níveis de volumoso. 1997. Tese (Doutorado em Zootecnia) - Universidade Federal de Viçosa. Viçosa, MG.

ASSOCIATION OF OFFICIAL ANALYTICAL CHEMISTS - AOAC. Official methods of analysis. 16. ed. Washington, 1995. $2000 \mathrm{p}$.

ATWELL, D. G.; MERCHEN, N. R.; JASTER, E. H; FAHEY JUNIOR, G. C.; BERGER, L. L.; TITGEMEYER, E. C.; BOURQUIN, L. D. Intake, digestibility, and in situ kinetics of treated wheat straw and alfalfa mixtures fed to holstein heifers. Journal of Dairy Science, Ithaca, v. 74, n. 10, p. 3524-3534, 1991.

BÜRGER, P. J.; PEREIRA, J. C.; SILVA, J. F. C.; VALADARES FILHO, S. B.; QUEIROZ, A. C.; CECON, P. R.; MONTEIRO, H. C. F. Consumo e digestibilidade aparente total e parcial em bezerros Holandeses alimentados com dietas contendo diferentes níveis de concentrado. Revista Brasileira de Zootecnia, Viçosa, v. 29, n. 1, p. 206-214, 2000.

CARDOSO, E. G. Engorda de bovinos em confinamento. Campo Grande: EMBRAPA CNPGC, 1996. 36 p. (Documentos, 64).

COSTA, C.; ARRIGONI, M. B.; SILVEIRA, A. C.; OLIVEIRA, H. N. Desempenho de bovinos superprecoces alimentados com silagem de milho ou feno de aveia e grãos de milho ensilados ou secos. Acta Scientiarum. Animal Science, Maringá, v. 24, n. 4, p. 1175-1183, 2002.

FREITAS NETO, M. D. Desempenho de bovinos mestiços leiteiros alimentados com diferentes níveis de concentrado na recria e terminação. 2009. Dissertação (Mestrado em Medicina Veterinária) - Escola de Veterinária, Universidade Federal de Goiás, Goiânia.

GOERING, H. K.; VAN SOEST, P. J. Forage fiber analysis: apparatus reagents, procedures and some applications. Washington, D. C: Agricultural Handbook, 1970. $379 \mathrm{p}$.

GRANDINI, D. Dietas contendo grãos de milho inteiro sem fonte de volumoso para bovinos confinados. In: SIMPÓSIO INTERNACIONAL DE NUTRIÇÃO DE RUMINANTES, 2., 2009, Botucatu. Anais... Botucatu: FCA-UNESP-FMVZ, 2009. p. 90-102.

LEÃO, J. P.; NEIVA, J. N. M.; RESTLE, J.; PAULINO, P. V. R.; SANTANA, A. E. M.; MIOTTO, F. R. C.; MISSIO, R. L. Consumo e desempenho de bovinos de aptidão leiteira em confinamento alimentados com glicerol. Ciência Animal Brasileira, Goiânia, v. 13, n. 4, p. 421-428, 2012.

LOPES, M. A.; SANTOS, G.; MAGALHÃES, G. P.; LOPES, N. M. Efeito do ganho de peso na rentabilidade da terminação em confinamento de bovinos de corte. Revista Brasileira Agrociência, Pelotas, v. 14, n. 1, p. 135-141, 2008.

MISSIO, R. L.; BRONDANI, I. L.; ALVES FILHO, D. C.; SILVEIRA, M. F.; FREITAS, L. S.; RESTLE, J. Comportamento ingestivo de tourinhos terminados em confinamento alimentados com diferentes níveis de concentrado na dieta. Revista Brasileira de Zootecnia, Viçosa, MG, v. 39, n. 7, p. 1571-1578, 2010.

NEUMANN, M.; RESTLE, J.; MÜHLBACH, P. R. F.; NÖMBERG, J. L.; ROMANO, M. A.; LUSTOSA, S. B. C. Comportamento ingestivo e de atividades de novilhos confinados com silagens de milho de diferentes tamanhos de partícula e alturas de colheita. Ciência Animal Brasileira, Goiânia, v. 10, n. 2, p. 462-473, 2009.

NEUMANN, M.; SANDINI, I. E.; OST, P. R.; FALBO, M. K.; LUSTOSA, S. B. C.; PELEGRINI, L. G. Desempenho de novilhos confinados alimentados com silagens de milho ou sorgo, associadas a três níveis de concentrado. Revista Brasileira de Milho e Sorgo, Sete lagoas, v. 6, n. 3, p. 365-378, 2007.

PEREIRA, M. N.; VON PINHO, R. G.; BRUNO, R. G. S.; CELESTINE, G. A. Ruminal degradability of hard or soft texture corn grain at three maturity stages. Scientia Agricola, Piracicaba, v. 61, n. 4, p. 358-363, 2004. 
RIBEIRO, T. R. Desempenho e qualidade de carcaça de bezerros holandeses alimentados com dietas contendo diferentes niveis de concentrado. 1997. Dissertação (Mestrado em Zootecnia) - Universidade Federal de Viçosa, Viçosa, MG.

ROCHA, E. O.; FONTES, C. A. A.; PAULINO, M. F.; LADEIRA, M. M. Ganho de peso, eficiência alimentar e características da carcaça de novilhos de origem leiteira. Revista Brasileira de Zootecnia, Viçosa, MG, v. 28, n. 1, p. 148-158, 1999.

RODE, L. M.; WEAKLEY, D. C.; SATTER, L. D. Effect of forage amount and particle size in diets of lactating dairy cows on site of digestion and microbial synthesis. Journal of Animal Science, Canadian, v. 65, n. 1, p. 101111, 1985.

SIGNORETTI, R. D.; SILVA, J. F. C.; VALADARES FILHO, S. B.; PEREIRA, J. C.; ARAÚJO G. G. L.; CECON, P. R.; QUEIRÓZ, A. C.; MUNIZ, E. B. Crescimento, conversão alimentar e rendimento de carcaça de bezerros da raça holandesa alimentados com dietas contendo diferentes níveis de volumoso. Revista Brasileira de Zootecnia, Viçosa, MG, v. 28, n. 1, p. 185194, 1999a.

SIGNORETTI, R. D.; SILVA, J. F. C.; VALADARES FILHO, S. B.; PEREIRA, J. C.; CECON, P. R.; QUEIRÓZ, A. C.; ARAÚJO G. G. L.; ASSIS, G. M. L. Consumo e digestibilidade aparente em bezerros da raça holandesa alimentados com dietas contendo diferentes níveis de volumoso. Revista Brasileira de Zootecnia, Viçosa, MG, v. 28, n. 1, p. 169-177, 1999 b.
SILVA, B. C.; PEREIRA, O. G.; PEREIRA, D. H.; GARCIA, R.; VALADARES FILHO, S. C.; CHIZZOTTI, F. H. M. Consumo e digestibilidade aparente total dos nutrientes e ganho de peso de bovinos de corte alimentados com silagem de brachiaria brizantha e concentrado em diferentes proporções. Revista Brasileira de Zootecnia, Viçosa, MG, v. 34, n. 3, p. 1060-1069, 2005.

SILVA, H. L. Dietas de alta proporção de concentrado para Bovinos de corte confinados. 2009. Tese (Doutorado em Ciência Animal) - Universidade Federal de Goiás, Goiânia.

SIMAS, J. M. C.; PIRES, A. V.; SUSIN, I.; SANTOS, F. A. P; MENDES, C. Q.; OLIVEIRA JÚNIOR, R. C; FERNANDES, J. J. R. Efeitos de fontes e formas de processamento do amido na utilização de nutrientes e parâmetros ruminais de vacas em lactação. Arquivo Brasileiro de Medicina Veterinária e Zootecnia, Belo Horizonte, v. 60, n. 5, p. 1128-1134, 2008.

STATISTICAL ANALYSIS SYSTEM INSTITUTE SAS Institute. SAS/STATÒ. User's guide: statistics, version 6. 4. ed. North Caroline, 1993. v. 2, 943 p.

UENO, R. K. Avaliação bioeconômica da cultura do milho (Zea mays L.) utilizada sob diferentes formas na alimentação de novilhos em confinamento. 2012. Dissertação (Mestrado em Agronomia) - Curso de PósGraduação em Produção Vegetal, Universidade Estadual do Centro-Oeste, Guarapuava.

VAN SOEST, P. J.; ROBERTSON, J. B.; LEWIS, B. A. Methods for dietary fiber, neutral detergent fiber, and nonstarch polysaccharides in relation to animal nutrition. Journal of Dairy Science, Ithaca, v. 74, n. 10, p. 35833597, 1991. 